2nd International Conference Art, Illustration and Visual Culture in Infant and Primary Education

\title{
La poética gráfica de Fernando Vilela
}

Laís Guaraldo lguaraldo@ua.pt

Universidade de Aveiro, Portugal

Reference

Guaraldo, Laís; (2012) "La poética gráfica de Fernando Vilela", p. 62-67 . In: Barbosa, Helena; Quental, Joana [Eds]. Proceedings of the 2nd International Conference of Art, Illustration and Visual Culture in Infant and Primary Education. São Paulo: Blucher, 2015. ISSN 2318-695X, ISBN: 978-989-98185-0-7 DOI 10.5151/edupro-aivcipe-13

Resumen

Este artículo se ocupará de un aspecto central del proceso de creación de elementos gráficos, como es el desarrollo del concepto visual de una publicación. Se analizarán los procedimientos relacionados con las elecciones visuales y gráficas del premiado libro "Lampião y Lancelote", con el propósito de reflexionar sobre los procedimientos y los retos involucrados en la definición de la unidad conceptual de la obra. La alteridad cultural y la tolerancia son temas recurrentes en la obra gráfica del artista brasileño Fernando Vilela- Ilena de encuentros, distanciamientos, enfrentamientos e identificaciones. En el caso del libro reseñado aquí, los dos personajes centrales juegan un papel emblemático -Lampião personifica la cultura de las tierras del interior semi-árido del nordeste de Brasil y Lancelote la tradición medieval europea. ¿Cómo traducir gráficamente el diálogo entre estos dos mundos? Lasrelaciones entre imágenes, palabras y contenido expresivo pueden ganar una gran complejidad cuando el trabajo se concibe como un todo. Mucho más que un relato ilustrado, podemos decir que este tipo de trabajo puede ser considerado como parte del género de "poesía gráfica".

Palabras clave proceso creativo, expresión gráfica, opciones visuales, Fernando Vilela, ilustración

\section{Abstract}

This article deals with this central aspect of the process of creating graphic elements, which is the development of the visual concept of a publication. We will analyze the procedures related to the choices in the award-winning graphic visualbook "Lampião e Lancelote", for the purpose of reflecting about the procedures and challenges involved in defining the conceptual unity of the work. The cultural otherness and tolerance are recurring themes in the graphic work of the Brazilian artist Fernando Vilela - full of meetings, estrangements, clashes and identifications. In the case of the book dealt with,, the two central characters play an emblematic role Lampião embodies the culture of the northeastern hinterlands of Brazil and Lancelot medieval European tradition. How to translate graphically the dialogue between these two worlds? The relationships between images, words and expressive content can achieve great complexity when the work is conceived as a whole. Much more than an illustrated narrative, we can say that this kind of work can be considered as part of the so called "graphic poetry. 
and International Conference Art, Illustration and Visual Culture in Infant and Primary Education
Congreso Internacional

Arte, Ilustración y Cultura Visual en Educación Infantil y Primaria
Congresso Internacional

de Arte, Ilustração e Cultura Visual

na Educação Infantil e Primária

\section{Introducción}

\subsection{Mestizajes gráficos}

Figura 1. Libro de Fernando Vilela: Lampião e Lancelote
Publicado en 2006, el libro "Lampião e Lancelote" ha recibido numerosos premios en Brasil y Europa. ¿Por qué este reconocimiento? El relato trata de un encuentro imaginario entre el caballero medieval Lancelote y la banda de Lampião, una figura histórica emblemática de las tierras del interior semi-árido de Brasil de finales del XIX al XX. El poder expresivo de la obra radica en la forma en que todos los elementos de la narración (texto, grafismo y formas plásticas) forman un conjunto integrado que narra una historia del encuentro entre diferentes culturas, con alejamientos, luchas y, finalmente, el diálogo. Además de la relevancia temática - la convivencia y la tolerancia entre las personas contra la diferencia, también la buena relación entre imagen y texto en esta estructura narrativa es digna de resaltar.

El análisis que aquí se propone tiene como base metodológica la crítica del proceso mediante el enfoque semiótico (Salles, 1999, 2006). Esta metodología propone la interpretación de movimiento creativo a partir del análisis relacional de diversos documentos generados en la producción de la obra y posteriormente.

La base de datos reunidos por el autor y también las entrevistas en las que explica su proceso se relacionan entre sí, generando un análisis de algunos de los ejes conductivos. ¿Cómo se produce este proceso de síntesis formal y la ejecución del proyecto? Estas son las preguntas a las que responde este artículo. El objetivo principal será evaluar las formas en que se construyó la ventaja visual. Sin embargo creemos necesario dar una pequeña explicación sobre la figura de Lampião y los salteadores de caminos, ya que creemos que es poco conocida por la opinión pública europea, para esclarecer las opciones tomadas por el autor. También es de interés aquí la dinámica de los signos, creados por el pueblo en ciertos contextos culturales, olvidados o rescatados y renacidos. Un conjunto simbólico de la Edad Media europea llegó a Brasil, al nordeste semiárido, de la mano de los portugueses, y esa región interior, lejos de la costa, llegó a tener su propia historia en la producción gráfica de la llamada "literatura del cordel". Este itinerario simbólico tiene un nuevo significado en la obra gràfica de Fernando Vilela.
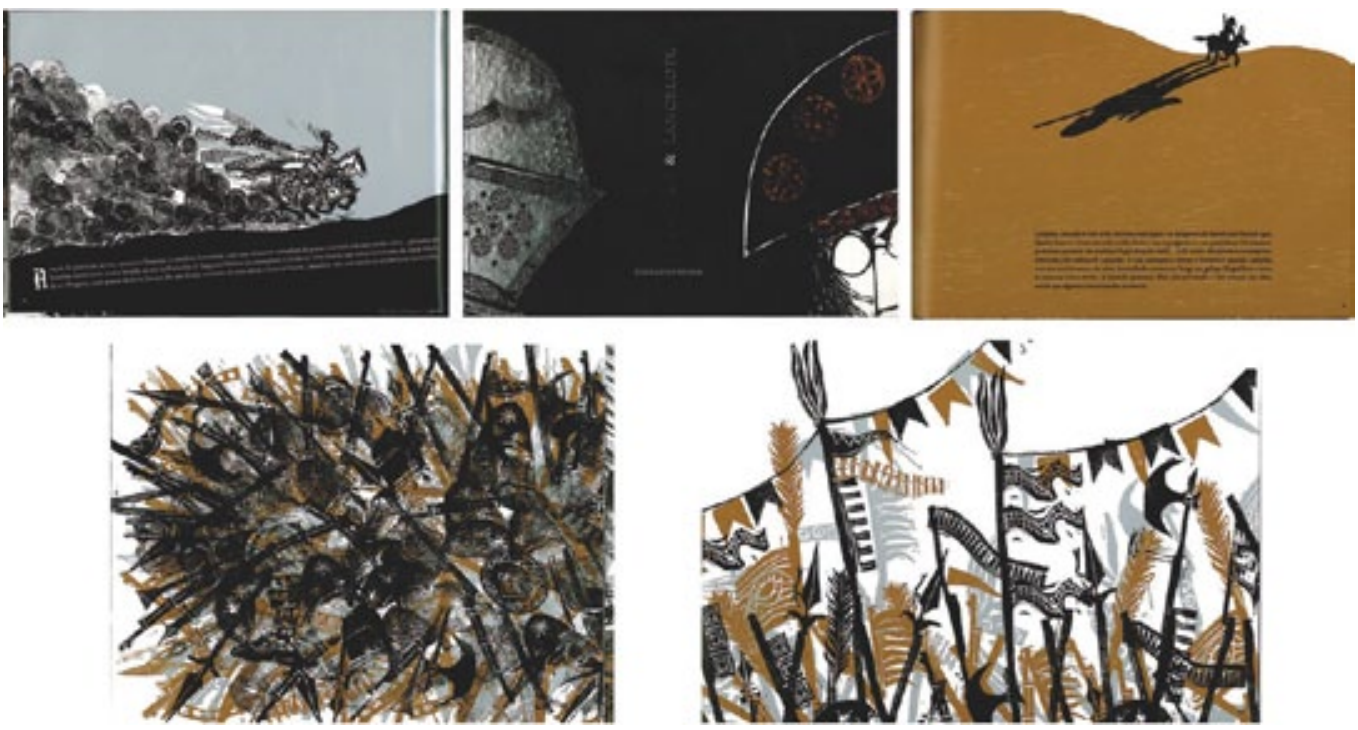

La intención es crear un encuentro fantasioso entre dos grandes guerreros y sus respectivas culturas: en la mano un Lanzarote - Caballero de la Mesa Redonda, un personaje de leyendas medievales relacionadas con el Rey Arturo. Por otro lado Lampião, un hombre real, un insurgente (Mello, 2010), vanidoso, el cabecilla de un grupo de justicieros, acuñando una marca de identidad tan fuerte que después de su muerte se convirtió en un mito y hasta el 
$2^{\text {nd }}$ International Conference Art, Illustration and Visual Culture in Infant and Primary Education $2^{\circ}$ Congreso Internacional

Arte, llustración y Cultura Visual en Educación Infantil y Primaria de Arte, llustração e Cultura Visual

na Educação Infantil e Primária presente protagoniza historias de "cordel", cantos, películas y canciones brasileñas. Alrededor de estos dos núcleos diferentes, el autor llevó a cabo varias investigaciones en un proceso de acercamiento al universo de los personajes, análisis de contenidos (verbal y visual) y la formulación de soluciones gráfico-narrativas. En el inicio del trabajo, se prestó una especial atención a los puntos de contacto entre dos culturas: la ropa, las armas y los animales utilizados para la locomoción. Este análisis de datos ha añadido nuevas capas de complejidad para el trabajo, nuevos encuentros.

Además del conocimiento de historias y leyendas sobre la Mesa Redonda, que poblaron la imaginación de este autor desde la infancia, Vilela investigó manuscritos, frescos, armas medievales y armaduras en varias colecciones de los museos en Londres, París, Nueva York, Washington DC y San Pablo. Fotografió y conservó material iconográfico de esas investigaciones, material que utilizó como base de una serie de dibujos y que le ayudó a formular su lengua de trabajo.

Buscó el imaginario iconográfico de Lampião en las publicaciones de "cordel" y en las xilografías populares. Este tipo de producción narrativa y gráfica tiene su origen en la Península Ibérica y todavía está muy presente en la región de los bandoleros, donde el personaje de Lampião es un muy común, protagonizando escenas como el encuentro con el diablo en la entrada del infierno.

Los "cangaceiros", eran bandas armadas de justicieros, en las que se incluían mujeres. Eran nómadas y se desplazaban hábilmente por la "caatinga" brasileña -región semiárida, con vegetación espinosa. Vilela, como parte de sus estudios en torno a la figura de Lampião y su bando, tuvo acceso a una colección original de trajes de los cangaceiros². Esta colección, organizada por el historiador Frederick P. De Mello, muestra una asombrosa profusión de ornamentos. Si el vestuario del vaquero del interior ("sertanejo") se caracteriza por su funcionalidad (ropa de cuero adecuado para el calor extremo y vegetación espinosa), ¿cómo explicar este exceso ornamental?

Mello publicó en 2010 el libro "La estética de los bandoleros." Los numerosos ejemplos que consiguió el investigador muestran como la cultura sertaneja se apropió de elementos de la cultura portuguesa de entre los años 1500 y 1700. Mello señala que los trajes y equipamiento de los cangaceiros tienen una estética afectada por un sistema de significados de la afirmación de la vida y de protección ante la muerte -tan presente en sus vidas. Un ejemplo es la "Estrella de Salomón", presente en los sombreros. Para los bandidos, esas estrellas desempeñan una función mágica: defender al portador de los maleficios que le desearan otros devolviéndolos a quien las viera.

Figura 2. Grabado en madera con Lampião y su esposa, bornal cangaceiro y fotografía de Lampião.
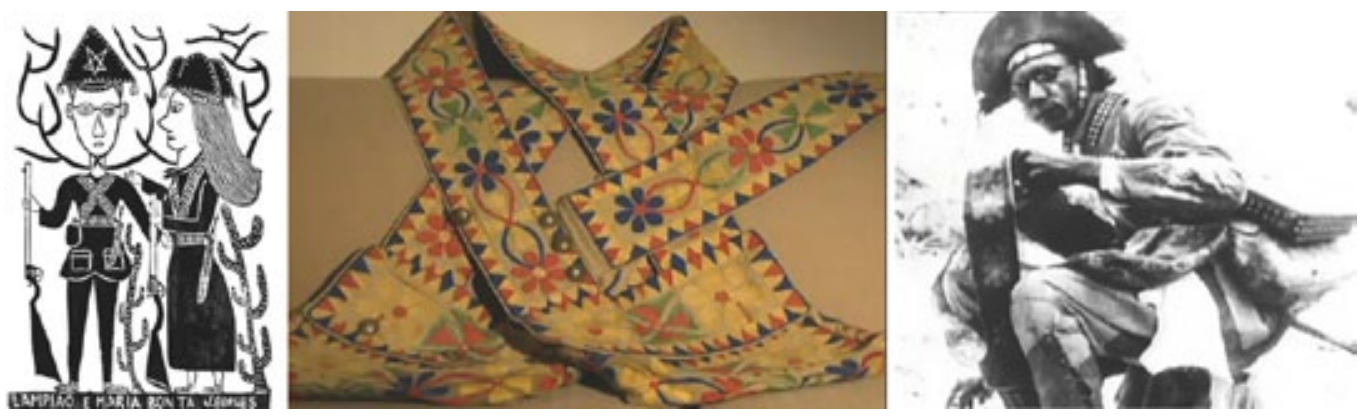

Lampião fue una figura paradójica. Varios testimonios lo describen como un hombre tranquilo y bien educado, hablaba en voz baja en tono amistoso, a quien le gustaban los perfumes y que llevaba anillos de oro y rubí. Pero al mismo tiempo, era un asesino. La creación de los adornos floridos en su vestimenta se atribuye à cangaceira Dadá. Lampião vio los adornos florales que le había hecho a su marido, el famoso Corisco, en un "bornal"3 y le pidió que los hiciera para él también. Desde ese momento, Lampião fomentó el uso de esa obra simbólica, incluso entre los líderes. Además de la función mágica de protección contra la muerte - que Mello llama "armadura mística", los adornos tenían una función de reafirmación de la identidad del grupo. 
$2^{\circ}$ Congreso Internaciona

Arte, Ilustración y Cultura Visual en Educación Infantil y Primaria $2^{\circ}$ Congresso Internacional

de Arte, llustracão e Cultura Visual

na Educação Infantil e Primária

\subsection{La unidad conceptual}

Este episodio de la vestimenta muestra la conciencia mediática de Lampião, que comprendía que esas flores y estrellas tenían un papel más allá del puramente ornamental. Este tipo de marca gráfica identitaria estará muy presente en el trabajo de Vilela.

La pieza gráfica que se analiza en este trabajo fue escrita e ilustrada por el autor mismo, dando como resultado un proceso donde se resaltó lo que Vilela considera como "un matrimonio del texto con la imagen". El autor comenta que en este tipo de producción narrativa "el texto y la imagen nacen juntos y van jugando hasta que encuentran los pasos correctos de la danza". ${ }^{4}$

Hemos visto en la exposición sobre los bandidos una serie de aspectos convergentes con la cultura medieval europea, que muestran como la aparente diferencia cultural no es tan lejana. ¿Cómo crear una identidad gráfica que dé unidad a la obra y, simultáneamente, haga referencia a la diversidad cultural de los personajes?

Las referencias literarias utilizadas para elaborar los textos eran las novelas de caballerías y la literatura de "cordel", una producción gráfica realizado en xilografía que aún se utiliza hoy en gran escala en la cultura propia "sertaneja" y que tuvo su origen en la Península Ibérica. E discurso de Lampião fue construido en sextillas - seis versos poéticos con siete sílabas cada uno. El habla de Lancelote lo escribió utilizando siete versos, para dar más sofisticación al caballero medieval.

Según Vilela (quien acostumbraba a hacer sus propias xilografias), "cordeles" como los de J. Borges mantienen hasta el presente el control artesanal de los orígenes de la producción gráfica y crean el máximo de poesía con el mínimo de recursos. Pero en el momento de la concepción visual de esta obra, el autor señala que esta característica podría ser un poco estática y no respondía al dinamismo que él pretendía. La solución que encontró para darle esa movilidad que deseaba fue el uso de la goma de borrar escolar, que utilizó como sellos de goma 5 . Son módulos formales y también semánticos. Torres medievales, armas, sombreros, caballos, banderas están dispuestos en forma organizada y articulados en la presentación de ambos mundos, pero después ganan movimiento y llegan a la cima de la desorganización entrópica, para posteriormente reorganizarse en una especia de fiesta de signos de ambas culturas.

Ambos personajes tienen sus accesorios marcados con los grafismos que les dan identidad. Signos adecuados de estampados medievales ( de paños y armas) constituyen el yelmo de Lancelote. Las impresiones de Lampião hacen referencia a los motivos de los diseños decorativos originales de las mochilas, sombreros y armas. La xilografía fue utilizado como fondo - para representar el espacio del "sertão", y en algunos momentos a Lampião, ya que, según el autor, su lenguaje es sencillo, negro, estéril, y tiene la dureza de la "caatinga".

La reducción de la paleta de colores, según el autor, da una mayor fuerza visual y expande el potencial simbólico del color dentro de la narración. La elección del color de los reflejos y el negro fueron fundamentales para la fuerza poética de la obra, pues además de ser poco comunes, traducen con densidad los contenidos relacionados con la abundancia de metales de las armas, el fuerte calor del "sertão" y la luz que cae sobre la sequedad de la "caatinga". Un mundo de colores metálicos y negros, que hacen referencia a una atmósfera irreal, destacando algunos de sus aspectos concretos: las ropas de los bandidos tenían también muchas medallas y condecoraciones de metal (además hacen referencia al oro robado y a las armas de fuego y las balas que llevaban). Al otro lado del Atlántico, las iluminaciones medievales asociaban los colores metálicos con lo sagrado (al fin y al cabo, Dios era considerado como la Luz).

El mundo de Lancelote es de plata, el de Lampião es color de cobre de la "caatinga" es de color negro. Con la presentación de los personajes el lector pronto se da cuenta esa sintaxis y a partir de ahí, esos colores pasan a tener vida propia en ese diálogo, duelo y comprensión entre dos diferentes. Así como hemos visto el movimiento de los signos gráficos creados con la goma: una combinación entre la presentación, la entropía y la reorganización, los colores siguen la misma dinámica. Y también el texto. 
2nd International Conference Art, Illustration and Visual Culture in Infant and Primary Education (n) de Arte, Ilustração e Cultura Visual na Educação Infantil e Primária
"Mi gente aqui termina

esta historia real

con baile, batalla y rima

con la ginga brasileña." bajar una barrera

dio lugar a una mermelada

de magia europea

\section{Conclusión}

Vilela no ve el trabajo de la ilustración como una traducción literal, sino como una creación plástica-poética que se apropia de elementos de la narración y realiza una interpretación con los recursos gráficos. Pero en el caso de este trabajo, lo que ocurre va más allá de la interpretación no literal de la imagen en relación con el texto. Se ve una construcción del significado combinada de tal manera que el conjunto de los elementos, verbales y visuales, construyen una narrativa en sinergia. A este poder expresivo le llamamos "poesía gráfica": un lenguaje híbrido que materializa su objeto, la lejanía y la diversidad cultural. Las relaciones entre imágenes, palabras y contenido expresivo ganan en mayor complejidad cuando se concibe la obra como un todo. Mucho más que un relato ilustrado, podemos decir que este tipo de trabajo puede ser considerado como dentro del género de "poesía gráfica".

El propósito de este trabajo fue demostrar la forma en que se estructuró una narrativa gráficopoética que trata sobre el encuentro y el diálogo entre diferentes - el hallazgo de una unidad plural. Esta relación entre la pluralidad y la unidad es también el gran desafío de la expresión gráfica: crear una identidad unificadora y, al mismo tiempo, un sistema que permite una variedad de elementos.

Vilela reconoce que aunque el texto surja junto con las imágenes, antes "es la idea de que se posa en nuestra cabeza"6. Machado de Assis escribió en su historia "un brazo" que algunas ideas son de la familia de las moscas tercas: por mucho que la gente se las sacuda, vuelven a posarse. ¿Cuál era la idea de que "se posó en su cabeza" y fue tomando forma? Obviamente no estamos hablando aquí del texto verbal, sino un propósito vago que se fue estructurado a medida que la investigación fue ganando cuerpo y los experimentos y las decisiones graficas maduraron. No se pretende aquí evaluar lo que vino antes o después. Por el contrario, resaltar los datos que muestran que la materialización de esta "idea" en partes visuales tuvo un proceso conjunto y combinado con la investigación y las decisiones de carácter estructural.

Para la critica del proceso con un enfoque semiótico, el proceso de creación, así como cualquier proceso semiótico, siempre está impregnada de la vaguedad y la incertidumbre. Sin embargo, el movimiento de interpretación sígnica es permanente y este proceso de significación lentamente puede generar sistemas más complejos.

En narraciones como ésta, los recursos visuales no desempeñan papeles redundantes o de simple ornamento del texto, son elementos estructurales. Este tipo de expresión visual gráfica altamente cargada de significado tiene mucho que enseñar a aquellos que, de alguna manera, participan en este momento de redefinición de los paradigmas de tantas narrativas, provocado por las nuevas tecnologías digitales. Aquí podemos ver como la contemporaneidad de una obra no está en el uso de esta o aquella herramienta semiótica, sino en cómo se accionan los recursos del lenguaje (de diferentes épocas) para dar fuerza expresiva a esta sensibilidad contemporánea frente a la diversidad y tolerancia cultural, donde lo metálico convive con lo oscuro de la xilografía.

\section{Referencias bibliográficas}

Assis, M. de. (1994) Obra Completa - v. II. Rio de Janeiro: Nova Aguilar. Baxandall M. (2006). Padrões de Intenção. São Paulo: Cia das Letras.

Guaraldo, L. (2007) A construção da linguagem gráfica na criação de ilustrações jornalísticas. Tese de doutorado. PUCSP. 
$2^{\text {nd }}$ International Conference Art, Illustration and Visual Culture in Infant and Primary Education $2^{\circ}$ Congreso Internacional Arte, Ilustración y Cultura Visual en Educación Infantil y Primaria
Congresso Internacional

de Arte, Ilustracão e Cultura Visual na Educação Infantil e Primária

Lotman, I. La Semiosfera I. (1996) Madrid: Cátedra.

Mello, F. P. de. (2010). A Estética do Cangaço. São Paulo: Ed. Escrituras.

Pinheiro, A. (org.) (2009). O Meio é a Mestiçagem. São Paulo: Estação das Letras e Cores.

Salles, C. (1999). Gesto Inacabado. São Paulo: Anablume

Salles, C. (2006). Redes da Criação. Vinhedo: Horizonte

Vilela, F. (2006) Lampião \& Lancelote. São Paulo: Cosac Naify.

Vilela, Fernando. (2001) Revista FronteiraZ no. 6 (entrevista)

Vilela, Fernando. Entrevista concedida à revista Crescer. (acesso em 01/02/12). http://revistacrescer.globo. com/Crescer/o,19125,EFC1666893-5670,oo.html Referencias audio visuales

A Musa do Cangaço. Direção: José Umberto Dias. Brasil, 1982, 35mm, p\&b, 18', documentário. http://www. youtube.com/watch?v=YDPJYidXn6Q (acesso em 13/05/2012)

Mello, F. P. de. Entrevista a Francisco José. http://www.youtube.com/watch?v=HTKyKjdwDGA\&feature=rela ted (acesso em 13/05/2012) Mello, Frederico Pernambucano de. Entrevista a Francisco José. http:// www.youtube.com/watch?v=HTKyKjdwDGA\&feature=related (acesso em 13/05/2012) 